\title{
High-Entropy Alloys for Solid Hydrogen Storage: Potentials and Prospects
}

\author{
Thakur Prasad Yadav ${ }^{1} \cdot$ Abhishek Kumar $^{1} \cdot$ Satish Kumar Verma ${ }^{1} \cdot$ Nilay Krishna Mukhopadhyay $^{2}(\mathbb{D}$
}

Received: 5 October 2021 / Accepted: 27 December 2021 / Published online: 9 January 2022

(c) Indian National Academy of Engineering 2022

\begin{abstract}
Hydrogen storage is one of the most significant research areas for exploiting hydrogen energy economy. To store hydrogen with a high gravimetric/volumetric density, gaseous hydrogen storage systems require a very high-pressure compressed gas cylinder which is quite unsafe and the storage in the liquid form needs cryogenic containers to be maintained at roughly $20 \mathrm{~K}$ under ambient pressure because hydrogen has a very low critical temperature of $33 \mathrm{~K}$. However, hydrogen can be stored in solid materials with higher concentration of hydrogen compared to the gaseous and liquid hydrogen storage systems. It is therefore, worthwhile to look into the experimental and theoretical research on prospective hydrogen storage materials. The hydride-forming alloys and intermetallic compounds are found to be the most important families of hydrogen storage materials. Multicomponent alloys consisting of five or more principal elements, also known as high-entropy alloys appear to have potential for the development as hydrogen storage materials. Hydride-forming elements like Ti, Zr, V, Nb, Hf, Ta, La, $\mathrm{Ce}, \mathrm{Ni}$, and others have been shown to have hydrogen storage properties and the ability to produce single-phase high-entropy intermetallics. Here, attempts will be made to present a short review on utilization of multicomponent high-entropy alloys as solid hydrogen storage materials. Furthermore, we will also present some of our work on the synthesis, structural-microstructural characterization and hydrogen storage properties of $\mathrm{Ti}-\mathrm{Zr}-\mathrm{V}-\mathrm{Cr}-\mathrm{Ni}$ equi-atomic hydride-forming high-entropy alloys. From the preliminary investigation, the maximum storage capacity in this system was observed to be $1.78 \mathrm{wt} \%$, which is comparable to other hydrogen storage materials. The prospects of high-entropy-based alloys for hydrogen storage will be discussed.
\end{abstract}

Keywords Complex intermetallics $\cdot$ High-entropy alloys $\cdot$ Hydrogen energy $\cdot$ Hydrogen storage $\cdot$ High-entropy hydrides

\section{Introduction}

\section{General Overview of High-Entropy Alloys}

Multicomponent high-entropy alloys (HEAs) seem to have appeared to be one of the most promising materials because of its excellent mechanical, thermal and oxidation properties compared to that of pure metals and conventional alloys (Murty et al. 2019; Vaidya et al. 2019). It is emerging as

Nilay Krishna Mukhopadhyay

mukho.met@iitbhu.ac.in

1 Department of Physics, Institute of Science, Hydrogen Energy Centre, Banaras Hindu University, Varanasi, Uttar Pradesh, India

2 Department of Metallurgical Engineering, Indian Institute of Technology (Banaras Hindu University), Varanasi 221005, India a new class of structural and functional materials and has attracted intense attention in recent years (Yadav et al. 2017; Mishra et al. 2019, 2020). It is to be noted that Yeh et al. (2004a, b), Cantor et al. (2004) and Ranganathan (2003) reported independently their own research and initiated the area of multicomponent high-entropy alloys. In 1981, Brian Cantor with his student Alain Vincent conducted the first research in the area of multi-component alloys and summarized the findings in the undergraduate project thesis (Vincent 1981). They mixed several components in equal proportions and discovered that $\mathrm{Fe}_{20} \mathrm{Cr}_{20} \mathrm{Ni}_{20} \mathrm{Mn}_{20} \mathrm{Co}_{20}$ composition formed a single face-centered cubic (FCC) phase, as well as a wide range of equi-atomic multi-component alloys with six to nine elements, now known as the Cantor alloy. The single-phase multi-principal element alloys were also proposed by Huang and Yeh (1996) independently and this ground-breaking concept was advocated on the exploration of HEAs. It is interesting to mention 
that in the multi-principal element alloys, the high-mixing entropy (also known as configurational entropy) could play an important role in reducing the number of phases in the higher-order multicomponent alloys, thereby improving the material's properties. In contrast to typical conventional alloys, which are based on a single principal element, HEAs contain at least five or more principal elements, each with a concentration of 5-35 (at. \%), as illustrated in Fig. 1. The basic principle of HEAs is based on high-mixing or configurational entropy which can stabilize the single phase in multicomponent system (Mukhopadhyay 2015). In general, the configurational entropy of complex alloys is high in liquid as well as in completely random solid solution; however, HEAs tend to have solid solution structures rather than complex intermetallics due to high-entropy effect (Murty et al. 2019).

It may be worth mentioning that earlier a German scientist, Franz Karl Achard had studied the multi-component equi-mass alloys with five to seven elements much before in the late of eighteenth century; however, research findings were almost overlooked subsequently. This research finding was brought out in 1963 by Professor Smith and it was shown that most likely this was the first one such study carried out on multi-principal element alloys containing five to seven elements (Smith 1963). A classic review article on
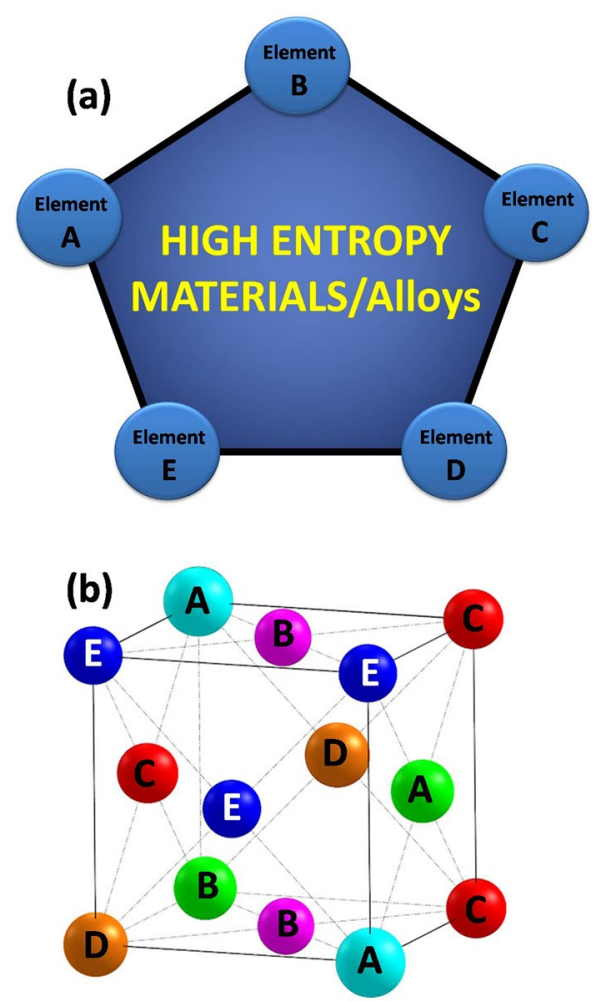

Fig. 1 a Schematic diagram of the HEAs containing five principal elements, $\mathbf{b}$ model of the structure with the concentration of elements ranging from 5 to 35 at $\%$ the 'Alloyed Pleasures: Multimetallic Cocktails' was published in 2003 by S. Ranganathan, who revealed the significance of this new class of alloys (Ranganathan 2003) while comparing with the multicomponent bulk metallic glasses. Accordingly, this new idea of the equi-atomic multi-component alloys is being explored for developments of novel materials. Thus, the possibility of exploitation of HEAs for various applications with a relatively low cost has attracted the attention of the materials research community (Mishra et al. 2021).

In multi-component intermetallics, it has been suggested that HEAs include high chemical disorder to stabilize disordered solid solution phases with simple crystal forms, such as body-centered cubic (BCC), face-centered cubic (FCC), and hexagonal close-packed (HCP) structures (Miracle and Senkov 2017). HEAs with a wide range of composition of 6-9 component alloys exhibited a majority phase being primary dendritic phase and they can dissolve substantial amounts of other transition metals after melt spinning or mechanical milling (Ye et al. 2016). Surprisingly, the alloys had just one main phase, and the overall number of phases was always substantially below the maximum equilibrium number of phases predicted by Gibbs Phase rule, and even lower than the maximum number allowed under non-equilibrium processing conditions (Tsai and Yeh 2014). Physical, chemical, mechanical, electrochemical properties, high-temperature strength and thermodynamic stability, adhesive wear properties, high hardness and strength properties, electrical and magnetic properties can be achieved in a wide range of HEAs (Sathiyamoorthi and Kim 2020; Basu and Hosson 2020; Yan and Zhang 2020; George et al. 2020; Zeng et al. 2021). These spectrums of properties are not often observed in the conventional alloys. However, the properties can further be influenced by the processing techniques. (Vaidya et al. 2019). The synthesis route can have a significant influence on the process of phase-choice and microstructural evolution (Sharma et al. 2018). Therefore, to develop technologically important materials for various application particularly the nuclear damage resistant materials, tool materials, turbine, aerospace materials, hydrogen storage etc., various issues related to structural stability and strengthening mechanisms are required to be investigated to improve the functional and structural properties of the HEAs. For example, tailoring of the microstructure and structure of multicomponent materials can obviously control the number of interstitial sites, which are very useful for effective hydrogen storage properties (Dornheim et al. 2006). While there is ongoing interest in the development of high-strength HEAs for energy-saving applications, such as transportation and energy, there have been only a few papers on hydrogen storage accessible to date (Edalati et al. 2020). It has been suggested that the complex intermetallics, such as multicomponent high-entropy Laves-phase and 
related alloys, can open a new area of research for developing hydrogen storage materials (Yadav et al. 2012a, b; Pandey et al. 2014). Therefore, designing a new equiatomic or non-equiatomic multicomponent HEAs will be extremely motivating and interesting (Mishra et al. 2021). Understanding towards evolution and stability of phases and microstructure for effective hydrogen storage is very much essential to design and develop HEAs as hydrogen storage materials for industrial applications. It need not be emphasized that a devoted attention and efforts are required to make availability of more efficient and clean alternative energy such as hydrogen (Pukazhselvan et al. 2012). Hydrogen economical system is based on the hydrogen production, storage, distribution and application (Yadav and Awasthi 2020). Here, attempts will be made to review the work on investigations for developing HEA-based hydrogen storage materials.

\section{Concept of Multicomponent High-Entropy Alloys}

\section{Thermodynamics Aspect}

Under isothermal and isobaric conditions, it is widely established in thermodynamics that a structure will aim to minimize its Gibbs free energy $(G)$, i.e., equilibrium will be reached when $\mathrm{G}$ achieves a minimum value. As a result, the following relationship exists for a system's free energy:

$G=H-T S$

It can be observed that a structure's enthalpy $(H)$ and entropy $(S)$ have a direct role in defining the equilibrium state at a particular temperature. The change of free energy $\left(\Delta G_{\text {mix }}\right)$ can be determined by comparing the free energy changes from the elemental state to various states to forecast the equilibrium state of a structure. The differences in free energy $\left(\Delta G_{\text {mix }}\right)$ and enthalpy $\left(\Delta H_{\text {mix }}\right)$ between the elemental and mixed states are related by Eq. (1):

$\Delta G_{\text {mix }}=\Delta H_{\text {mix }}-T \Delta S_{\text {mix }}$

The mixing configurational entropy of an $n$-element equimolar alloy transitioning from an elemental to a random solution state (ideal state or regular state) can be calculated using Boltzmann's hypothesis:

$\Delta S_{\text {mix }}=R \ln (n)$

where $R(8.31 \mathrm{~J} / \mathrm{mol})$ is the gas constant. Figure 2 shows the mixing entropy as a function of the number of components in the equiatomic alloys, as determined by equation number 3. Due to the limited number of ways ordered compound states can mix, mixing entropies are projected to be lower. HEAs have been identified as alloys that contain five to

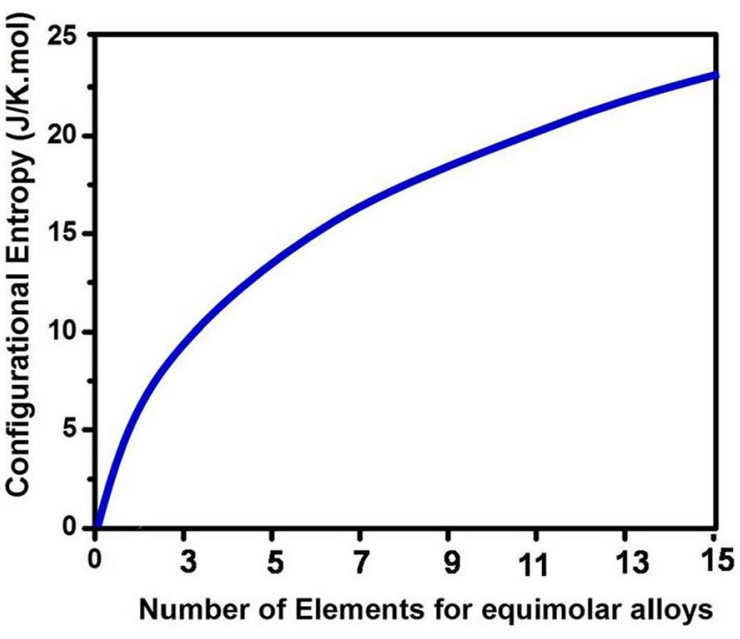

Fig. 2 Calculated entropy of mixing (also known as configurational entropy) as a function of the number of elements for equi-atomic alloys in the random solution state

thirteen primary elements based on calculations. The fiveelement lower limit is set because it is thought to be the point at which the mixing entropy is high enough $\left(\Delta S_{\text {mix }}=1.6 R\right)$ to counterbalance the positive enthalpy of mixing in most alloy systems, ensuring the formation of solid solution phases. The concentration of each element need not be equiatomic, but can be maintained between 5 and 35 at\%. As a result, unlike typical alloys, HEAs do not contain any elements with concentrations more than 35 at $\%$. It is accepted that in general equiatomic or non-equiatomic HEAs, the configurational entropy should lie in the range of $1.5 R$ and above to derive the benefits of entropy effects. However, other factors, such as enthalpy of mixing, lattice distortion (arising from the size difference of elements), valence electron concertation among other parameters, also have some significance while stabilizing a single-phase solid solution (Murty et al. 2019).

\section{Synthesis Techniques of HEAs}

Having discussed about the concept of high-entropy effect, now we can discuss briefly the fabrication techniques for synthesis of HEAs, involving a variety of processing routes (from solid, liquid or gaseous state), e.g., induction melting (IM), vacuum arc melting (VAM), mechanical alloying (MA), spark plasma sintering (SPS), melt spinning, sputtering, etc., as demonstrated in Fig. 3. However, one of the most successful synthesis techniques is the melting and casting route through vacuum arc/induction melting followed by solidification (Murty et al. 2019). Nowadays, another technique for synthesis of alloys/composites in nano-scale is high-energy ball milling (Yadav et al. 2012a, b). This material processing technique is very 


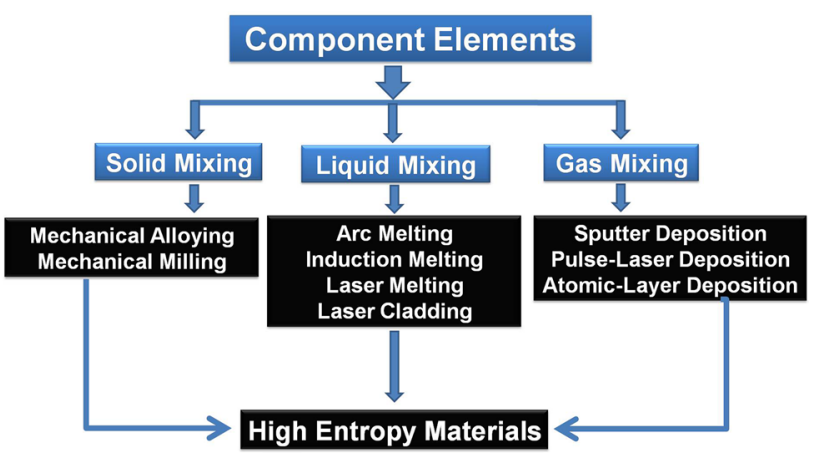

Fig. 3 Major processing routes for synthesis of HEAs involving solid, liquid, and gaseous states

efficient to achieve the homogeneous and also nanostructured materials (Murty and Ranganathan 1998; Mukhopadhyay et al. 2002). MA is processed by high-energy ball mill to ensure for homogeneity of materials among the immiscible elements for solid solution formation. During mechanical milling, continuous deformation, facture and particle welding lead to amorphization or nano-crystallization (Murty and Ranganathan 1998; Mukhopadhyay et al. 2003). MA technique has been extensively used for fabrication of intermetallics, amorphous materials and nanocomposites (Mukhopadhyay and Yadav 2011). Several HEAs have been synthesized in equi-atomic multicomponent alloy using MA. Here, we have mentioned some experimental details of how we synthesized earlier a multicomponent single-phase hexagonal C14-type Laves phase using radio-frequency induction melting followed by solidification (Yadav et al. 2017) using high-purity Ti (99.99\%), Zr (99.90\%), V (99.99\%), Cr (99.96\%), and $\mathrm{Ni}$ (99.99\%). All of the five elements in equiatomic ration were placed in a cylindrical steel molding and squeezed with a hydraulic press before being melted in an $18-\mathrm{kW}$ radiofrequency induction furnace with an argon gas supply. The as-cast and annealed HEAs were characterized by X-ray diffraction (XRD), scanning electron microscopy (SEM) and transmission electron microscopy (TEM). The particular characterization results have been shown in Fig. 4 (Yadav et al. 2017). It was clear that the as-cast alloy exhibited a pure hexagonal C14 Laves-phase structure $(a=5.08 \AA$ and $c=8.41 \AA)\left(\mathrm{MgZn}_{2}\right.$ type, space group $\mathrm{P} 63 / \mathrm{mmc}$ ) space group). After $24 \mathrm{~h}$ of isothermal annealing at $1173 \mathrm{~K}$ in vacuum, the HEA also exhibited hexagonal C14 Laves phase with an increase in the diffraction peaks' intensity (Fig. 4a). The isothermal annealed HEA
Fig. 4 X-ray diffraction (XRD) patterns of $\mathrm{Ti}-\mathrm{Zr}-\mathrm{V}-\mathrm{Cr}-\mathrm{Ni}$ high-entropy alloy a as-cast \& annealed; b scanning electron microscopy (SEM) image of fractured surface, $\mathbf{c}$ transmission electron microscopy (TEM) bright field micrograph and $\mathbf{d}$ corresponding selected area electron diffraction pattern of $\mathrm{Ti}-\mathrm{Zr}-\mathrm{V}-\mathrm{Cr}-\mathrm{Ni}$ high-entropy alloy (Yadav et al. 2017)
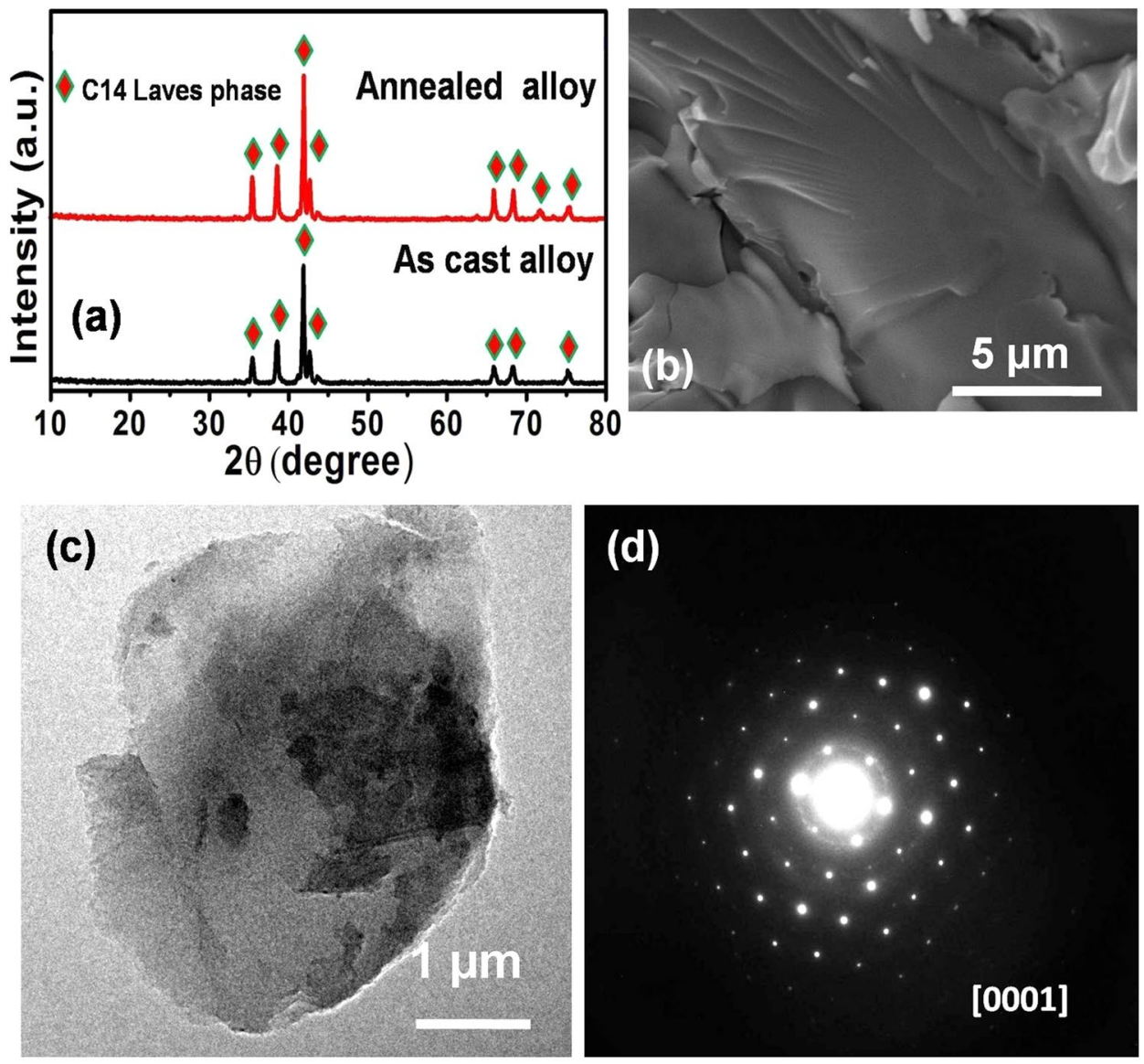
shows the cleavage steps and intergranular fracture on the normally broken surface as shown in Fig. 4b. Figure 4c, d depicts the annealed HEA's TEM microstructure and corresponding selected area electron diffraction (SAD) patterns. The SAD spots are highly sharp, which indicates that grain growth is expected to take place after annealing, and the alloy should be more ordered and defect-free. It will be shown in latter sections how this material consisting of single Laves phase responds during hydrogen absorption and desorption.

\section{Exploitation of Hydrogen Energy}

Energy, being a key pillar of human well-being, economic development and poverty alleviation, was made available from various resources, such as coal, petroleum, biomass, etc. Although these resources (fossil fuels) have sufficient attraction for energy demand, but their storage is not sufficient with long time durability. Moreover, the continued use of fossil fuels is causing major environmental concerns as well. Globally, after the United States of America (USA) and China, India is the third-largest energy consumer. The demand of consumption of energy (in form of oil, gas etc.) has been increased against the production in last few years (Srivastava et al. 2015). Hydrogen is an absolutely clean fuel that produces only water after use and it can be generated from different resources, such as biomass, natural gas, nuclear power, renewable power like solar, wind, etc. The use of hydrogen among all the available non-fossil energy resources mentioned above will be most effective for meeting our aspirations due to availability of the most abundant renewable fuel in nature. It can be used as a fuel in transportation, in houses, for portable power, and in many more applications. The chemical energy per unit mass of hydrogen gas $\left(\mathrm{H}_{2}\right)(142 \mathrm{MJ} / \mathrm{kg})$ is at least three times higher than that of other chemical fuels, for example, liquid hydrocarbons (diesel fuel, 42-46 MJ/kg, crude oil, 42-47 MJ/kg, liquefied petroleum gas (LPG), 46-51 MJ/kg). The cold hydrogen combustion in a fuel cell system generates electrical power, while hot hydrogen combustion in internal combustion (IC) engines or heat engines generates power in the same way that liquid hydrocarbons like petroleum does. Both the cold and hot combustion processes produce water in the case of hydrogen. Thus, hydrogen can be produced from water and it also produces water when it is burnt with oxygen. In spite of all such merits, a perfect hydrogen fuel-based economic system for vehicular applications (hydrogen economy) has not yet been framed due to technical challenges in areas of the hydrogen production, storage, and application (Verma et al. 2020). Among these three areas of challenges, hydrogen storage presents a key challenge due to its very low density $(0.08988 \mathrm{~g} / \mathrm{L})$. Hydrogen storage is the main issue for the development of hydrogen in applications as alternative energy source (Pandey et al. 2017).

\section{Utility of Hydrogen Storage Materials}

Though hydrogen has the highest energy value per mass of any fuel, it has the lowest energy per unit volume due to its low ambient temperature density. As a result, better storage technology and procedures with the potential for increased energy density must be developed urgently. In the current scenario of on-board applications, hydrogen is stored as a compressed gas in high-pressure tanks or as cryogenic liquid state (below the critical temperature $\sim 33 \mathrm{~K}$ ) or in the solidstate compounds, such as metal hydrides, complex hydrides or porous materials. The aspects regarding various options for storage are illustrated in Fig. 5 concerning the technical state and the viability in future applications.

On a unit mass basis, hydrogen gas offers an extraordinary energy value due to its low molecular weight and high molar combustion heat. However, because of its low density (in both liquid and gas form), hydrogen gas has a heating value per volume that is substantially lower than that of conventional fuels. e.g., coal and hydrocarbon. The solid-state storage appears to be a viable, efficient and safe mode of hydrogen storage, where hydrogen can be stored in a material either in the form of atoms or in the form of $\mathrm{H}_{2}$ molecules through two well-known processes, namely (i)

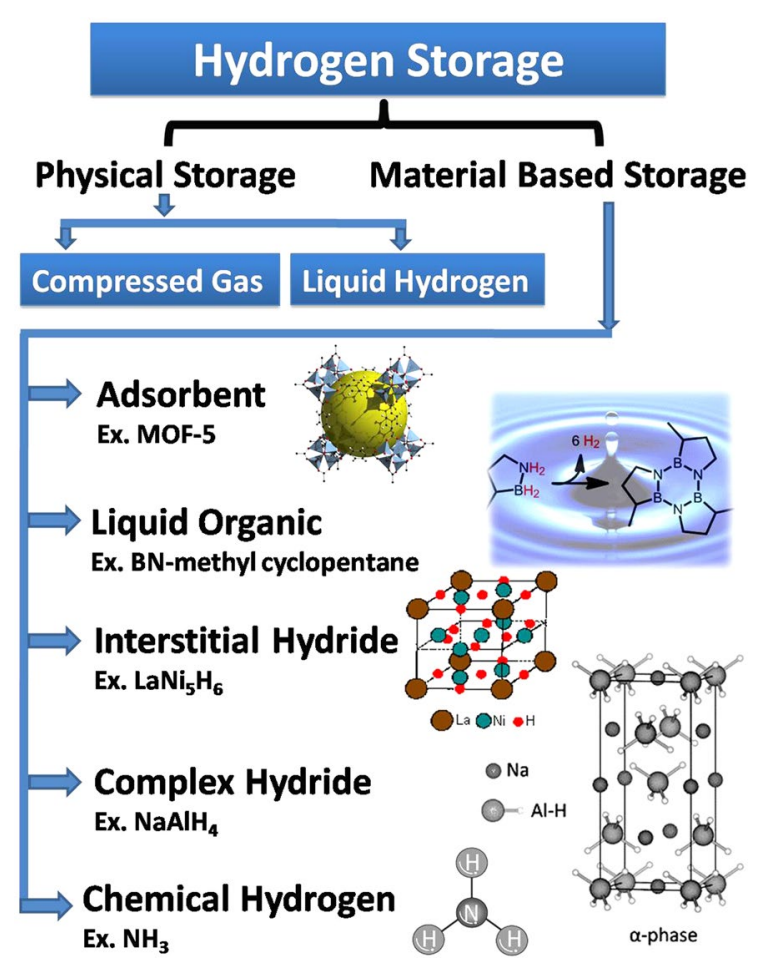

Fig. 5 Different methods and phenomena of the various hydrogen storage systems 
physisorption and (ii) chemisorption. Among various storage modes described above (like solid state, gaseous and liquid mode), solid-state storage modes in the form of metal/ intermetallic hydrides were found to be established first as efficient, safe and cost-effective option (Shahi et al. 2008, 2010, 2011). These hydrides have high volumetric hydrogen storage capacity as compared to other hydrogen storage options, such as high-pressure and liquid hydrogen storage.

Intermetallic hydrides are frequently formed by mixing elements that create a stable hydride with elements that form an unstable hydride. The intermetallic hydride's general formula is found to be $\mathrm{AB}_{x} \mathrm{H}_{n}$. The 'A' element is typically a rare-earth or alkaline earth metal that produces a stable hydride, whereas the ' $\mathrm{B}$ ' element is frequently a transition metal that forms only an unstable hydride. $x=0.5,1,2,5$ are some well-defined ratios of A to B in intermetallic compounds that generate hydrides with a hydrogen-to-metal ratio of up to 2 . The most common intermetallic compounds are suggested to be $\mathrm{AB}, \mathrm{A}_{2} \mathrm{~B}, \mathrm{AB}_{2}$ and $\mathrm{AB}_{5}$ types (Sakintuna et al. 2007). Ti, $\mathrm{La}, \mathrm{Ca}, \mathrm{Ce}, \mathrm{Sm}, \mathrm{Mg}$ and $\mathrm{Zr}$ are known to be hydride formers along with the other alloying elements, such as $\mathrm{Fe}, \mathrm{Ni}, \mathrm{Mn}, \mathrm{Cu}$ and $\mathrm{Al}$. The first-discovered compound of intermetallic family was reported to be $\mathrm{AB}_{5}$ type i.e., $\mathrm{LaNi}_{5}$. The maximum amount of hydrogen that can be accommodated in the hydride phase is estimated by the number of interstitial sites (tetrahedral and octahedral) that are available in the intermetallic compounds for which two criteria are applicable as shown in Fig. 6 (Switendick 1979). The inter-atomic distance $(D)$ between two atoms of hydrogen on interstitial sites should be at least $2.1 \AA$ and the Westlake criterion for the radius $(R)$ of largest sphere on an interstitial site touching all the neighboring metallic atoms should be $\sim 0.37 \AA$ (Westlake 1983).

There are many aspects to be considered while choosing any intermetallic compound for hydrogen storage application (Rai et al. 2009; Yadav et al. 2012a). We must consider thermodynamic properties, such as plateau pressure at various temperatures, plateau slop and the pressure difference between absorption and desorption, ease of activation, mechanical strength, cyclic stability, such as hydrogen charge-discharge behavior, ductility, and methodology of
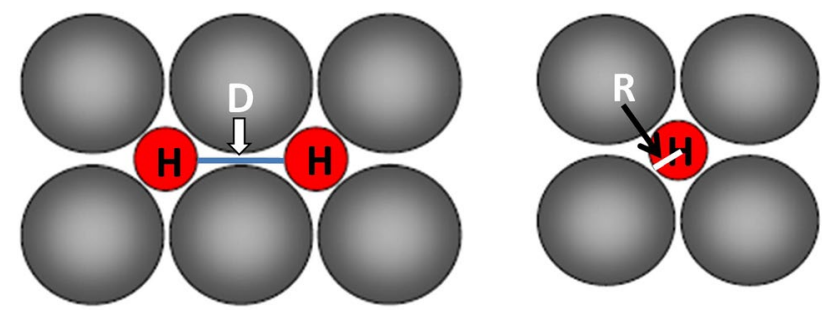

Fig. 6 The inter-atomic distance between two atoms of hydrogen at interstitial sites and the radius of largest sphere to be accommodated in the interstitial site intrinsic and extrinsic testimonies. The other prominent aspects for selecting any intermetallics for hydrogen storage are hydrogen capacity, energy density and enthalpy of dehydrogenation. The value of enthalpy varies from 30 to $70 \mathrm{~kJ} / \mathrm{mol}^{-\mathrm{H}_{2}}$ (Shahi et al. 2015, 2017). Since two or more metallic elements in hydride-forming intermetallics are normally considered to be good hydrogen storage materials; therefore, there is a possibility of developing effective hydrogen storage materials from HEAs containing a large number of hydride-forming elements.

\section{Hydrogen Storage in HEAs}

As it is understood that hydrogen can be stored in the chemical form in metal hydrides due to their strong tendency to form covalent bonds with metallic atoms at room temperatures; hence, metal and alloys can absorb hydrogen easily. However, to use hydrogen as a fuel, the desorption of hydrogen needs to be facilitated as well, which becomes difficult in metal due to their strong bonding with hydrogen making them too stable to release the stored hydrogen at room temperature. Hence, high temperatures around $120-200{ }^{\circ} \mathrm{C}$ are generally required for releasing hydrogen. To reduce this temperature (energy input), new types of materials have to be developed and this leads the researchers to explore the fabrication of high-entropy alloys consisting of hydrideforming elements where the elements form weaker bonds with hydrogen, facilitating desorption of the stored hydrogen. This option of involving multicomponent elements makes the HEAs to be potential hydrogen storage materials. Some investigated HEAs-based hydrogen storage materials have been listed in Table 1.

Most of the research with high hydrogen storage capacity has been focused on the Ti-V-based solid solution metal hydrides with body-centered cubic (BCC) structure (Pandey et al. 2014). For transition metals like $V$, the rate of hydrogen diffusion is extremely high. Although alloying with Ti slows the rate of diffusion, the Ti-V alloy has a larger hydrogen content than $\mathrm{V}$ alone. Ti-V-Cr alloys, in particular, have demonstrated remarkable hydrogen storage characteristics. Although adding $\mathrm{Cr}$ to a Ti-V alloy improves its desorption capability, it makes the alloy more difficult to activate. It has been reported that an alloy with the composition $\mathrm{Ti}_{2} \mathrm{CrV}$ may absorb up to $4.37 \mathrm{wt} \%$ hydrogen at room temperature (Kumar et al. 2012). However, it suffers from difficulty in activation and comparatively higher desorption temperature, hindering its practical application as hydrogen storage material. As a result, developing the microstructure of hydrogen storage HEAs is critical, as the quantity of interstices available for hydrogen atoms is influenced by their structural parameters. For example, the Laves phase based alloys seem to be a new area of research for developing efficient hydrogen storage materials. At ambient temperature and pressure, some of the 
Table 1 Investigations on some HEA-based hydrogen storage materials

\begin{tabular}{|c|c|c|c|c|c|}
\hline S. no & Alloy composition/system & Synthesis method & Structure & $\begin{array}{l}\text { Storage } \\
\text { capacity } \\
(\mathrm{Wt} \%)\end{array}$ & References \\
\hline 1 & $\mathrm{CoFeMnTi}_{\mathrm{x}} \mathrm{V}_{\mathrm{y}} \mathrm{Zr}_{\mathrm{z}}$ & Arc melting & C14 Laves phase & $0.03-1.80$ & Kao et al. (2010) \\
\hline 2 & $\mathrm{ZrTiVCrFeNi}$ & LENS & C14 Laves phase & 1.81 & Kunce et al. (2013) \\
\hline 3 & TiZrNbMoV & LENS & $\mathrm{BCC}$ & 2.30 & Kunce et al. (2014) \\
\hline 4 & $\mathrm{Ti}_{0.325} \mathrm{~V}_{0.275} \mathrm{Zr}_{0.125} \mathrm{Nb}_{0.275}$ & Arc melting & $\mathrm{BCC}$ & 2.5 & Montero et al. (2019) \\
\hline 5 & TiVZrNbHf & Arc melting & $\mathrm{BCC}$ & 2.70 & Sahlberg et al. (2016) \\
\hline 6 & TiZrNbHfTa & Arc melting & $\mathrm{BCC}$ & $2.00 \mathrm{H} / \mathrm{M}$ & Zlotea et al. (2018) \\
\hline 7 & $\mathrm{MgZrTiFe}_{0.5} \mathrm{Co}_{0.5} \mathrm{Ni}_{0.5}$ & MA & FCC & 1.2 & Zepon et al. (2018) \\
\hline 8 & TiZrHfMoNb & Arc melting & $\mathrm{BCC}$ & 1.18 & Shen et al. (2019) \\
\hline 9 & TiZrNbTa & Arc melting & $\mathrm{BCC}$ & 1.40 & Zhang et al. (2019) \\
\hline 10 & $\mathrm{Ti}_{0.20} \mathrm{Zr}_{0.20} \mathrm{Hf}_{0.20} \mathrm{Nb}_{0.40}$ & Arc melting & $\mathrm{BCC}$ & 1.12 & Shen et al. (2020) \\
\hline 11 & $\mathrm{MgVAlCrNi}$ & MA & $\mathrm{BCC}$ & 0.30 & Strozi et al. (2021) \\
\hline 12 & $\mathrm{MgVTiCrFe}$ & MA & $\mathrm{BCC}$ (major), and $\mathrm{MgH}_{2}$ (minor) & 0.30 & Marco et al. (2020) \\
\hline 13 & TiVZrNbTa & Arc melting & $\mathrm{BCC}$ & 2.50 & Montero et al. (2020) \\
\hline 14 & $\mathrm{Ti}_{0.30} \mathrm{~V}_{0.25} \mathrm{Zr}_{0.10} \mathrm{Nb}_{0.25} \mathrm{Ta}_{0.10}$ & Arc melting & $\mathrm{BCC}$ & 2.2 & Montero et al. (2020) \\
\hline 15 & CoFeMnTiVZr & Arc melting & C14 Laves Phase & 1.91 & Sarac et al. (2020) \\
\hline 16 & AlCrFeMnNiW & MA & BCC (major), and FCC (minor) & 0.62 & Dewangan et al. (2020) \\
\hline 17 & TiZrHfMoNb & Arc melting & $\mathrm{BCC}$ & 1.18 & Shen et al. (2020) \\
\hline 18 & $\mathrm{Mg}_{0.10} \mathrm{Ti}_{0.30} \mathrm{~V}_{0.25} \mathrm{Zr}_{0.10} \mathrm{Nb}_{0.25}$ & MA & $\mathrm{BCC}$ & 2.7 & Montero et al. (2021) \\
\hline 19 & $\mathrm{TiZrNbCrFe}$ & Arc melting & C14 Laves Phase (major), BCC (minor) & 1.9 & Floriano et al. (2021a, b) \\
\hline 20 & MgAlTiFeNi & MA & BCC And $\mathrm{TiH}_{2}$ & 1.0 & Cardoso et al. (2021) \\
\hline 21 & $\mathrm{Mg}-\mathrm{V}-\mathrm{Al}-\mathrm{Cr}-\mathrm{Ni}$ & MA & $\mathrm{BCC}$ & 0.3 & Strozi et al. (2021) \\
\hline 22 & $\mathrm{Ti}-\mathrm{Zr}-\mathrm{V}-\mathrm{Cr}-\mathrm{Ni}$ & Induction melting & C14 Laves & 1.78 & Present work (2021) \\
\hline
\end{tabular}

LENS laser engineered net shaping, $M A$ mechanical alloying, $B C C$ body-centered cubic, $F C C$ face-centered cubic

investigated $\mathrm{Zr} / \mathrm{Ti}-\mathrm{V}$ and $\mathrm{Zr} / \mathrm{Ti}-\mathrm{V}-\mathrm{X}(\mathrm{X}=\mathrm{Fe}, \mathrm{Mn}, \mathrm{Co}, \mathrm{Cr}$, or $\mathrm{Ni}$ ) alloys had a reasonably significant hydrogen capacity of $1.7 \mathrm{wt} \%$ as well as quick hydrogen absorption and desorption kinetics. (Edalati et al. 2020). As a result, the development of new equiatomic or non-equiatomic multi-component HEAs based on hydride-forming elements is extremely motivating, particularly in terms of understanding the evolution of different phases and microstructures that would be beneficial for hydrogen storage and their relative stability during absorption and desorption cycles. In HEAs, the Laves phases are usually found coexisting with other phases. The formation of a single-phase high-entropy intermetallic Laves-type phase in $\mathrm{Ti}-\mathrm{Zr}-\mathrm{V}-\mathrm{Cr}-\mathrm{Ni}$ equiatomic alloy was first described by Yadav et al. (2017). Recently, transformation of a single C14type Laves phase to BCC-phase was observed due to the addition of $\mathrm{Fe}$ in $\mathrm{Ti}-\mathrm{V}-\mathrm{Cr}-\mathrm{Ni}-\mathrm{Zr}-\mathrm{Fe}_{\mathrm{x}}$ system (Mishra et al. 2021).

\section{Ti-Zr-V-Cr-Ni HEAs for Effective Hydrogen Storage}

The range of possible HEA compositions is enormous, and thermodynamic-based design methods can provide good predictions about phase formation and stability in various
HEAs. These thermodynamic techniques enable more alloys to be designed with a better fundamental understanding and practical applicability. As discussed earlier, HEAs synthesized by hydride-forming elements have an outstanding possibility to store the hydrogen with a variable hydrogen-tometal (H/M) ratio. High-entropy hydrides (HEHs), a form of hydrogen storage HEA, have exceptional hydrogen storing potential (Floriano et al. 2021a, b). The Ti-Zr-Nb-Cr-Fe alloy, on the other hand, showed a dominant presence of a solid solution C14 Laves phase (98.4\%), with a minor proportion of a disordered BCC phase (1.6\%). Therefore, synthesis of C14-type high-entropy Laves phase and an investigation on its hydrogen storage behavior are of significance. As mentioned in the earlier section that a single $\mathrm{C} 14$ Laves phase was synthesized in $\mathrm{Ti}-\mathrm{Zr}-\mathrm{V}-\mathrm{Cr}-\mathrm{Ni}$ equiatomic alloy and the same alloy has been tested for hydrogen absorption and desorption experiments. The hydrogen storage pressure composition isotherm (PCI) curve obtained from our preliminary experiments is shown in Fig. 7a. The experimental $\mathrm{PC}$ isotherm observation was carried out at $150{ }^{\circ} \mathrm{C}$ temperature; however, the sample was activated at $400{ }^{\circ} \mathrm{C}$ for $5 \mathrm{~h}$ under $\sim 10^{-8}$ atm pressure. It can be clearly seen that most of the hydrogen was stored (1.4 wt \%) below $10 \mathrm{~atm}$ and the 

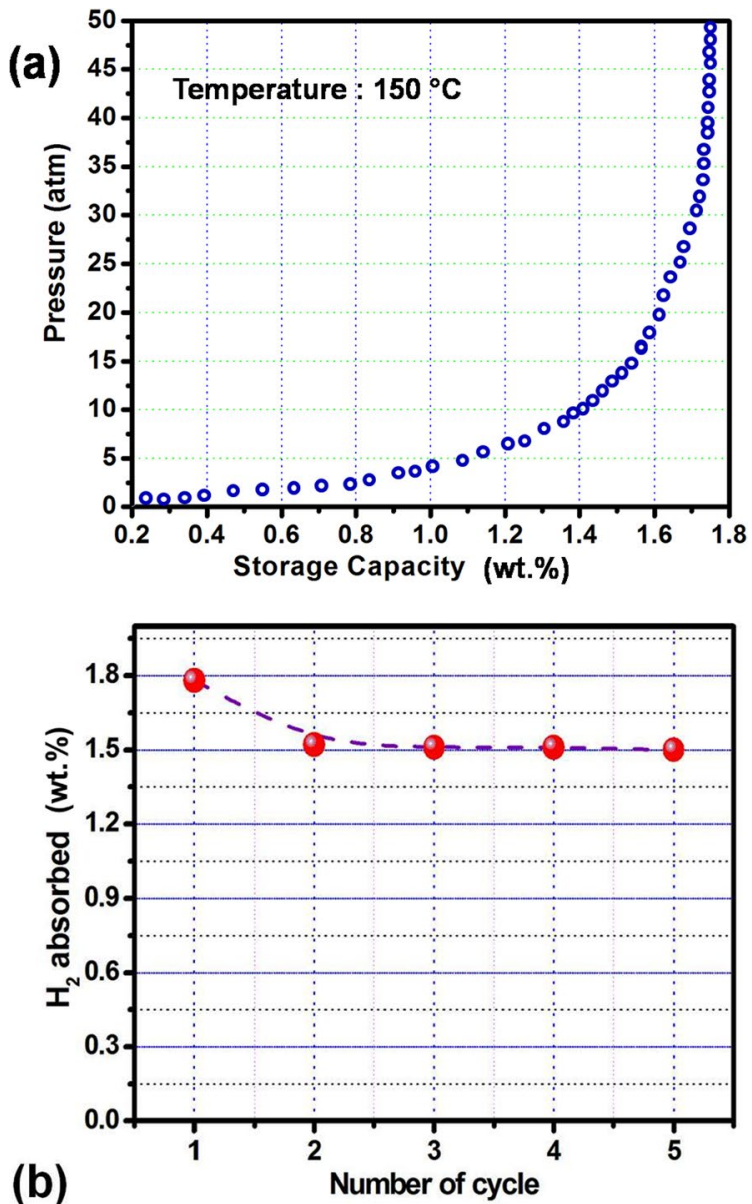

Fig. 7 a Pressure composition isotherm (PCI) of $\mathrm{Ti}-\mathrm{Zr}-\mathrm{V}-\mathrm{Cr}-\mathrm{Ni}$ high-entropy alloy for absorption, b cyclic stability curve up to 5 cycles under PCI mode

maximum storage capacity has been observed $\sim 1.78 \mathrm{wt} \%$, which is higher value compared to the well-known LaNi system ( 1.55 wt\%) (Srivastava and Srivastava 1999). The PCI hydrogen storage capacity was measured up to 5 repeated cycles to notice the cycling stability of the sample as shown in Fig. 7b. After each absorption cycle, the testing reactor along with $\mathrm{Ti}-\mathrm{Zr}-\mathrm{V}-\mathrm{Cr}-\mathrm{Ni}$ alloy was heated at $250^{\circ} \mathrm{C}$ under continuous running of rotary pump for $2 \mathrm{~h}$ and testing reactor pressure was maintained at $\sim 10^{-5}$ atm. This is a kind of activation of $\mathrm{Ti}-\mathrm{Zr}-\mathrm{V}-\mathrm{Cr}-\mathrm{Ni}$ alloy after each cycle; further sample was cooled down up to $150{ }^{\circ} \mathrm{C}$ and was conducted continuous hydrogenation under PCI mode. It is clear from Fig. 7b, i.e., from cyclic stability curve; the $\mathrm{Ti}-\mathrm{Zr}-\mathrm{V}-\mathrm{Cr}-\mathrm{Ni}$ alloy sample absorbs $1.78 \mathrm{wt} \%$ in the first cycle; however, the storage capacity deteriorates in the second cycle up to $\sim 1.5 \mathrm{wt} \%$ and further it was nearly constant in the third, fourth and fifth cycles. The stability curve was observed at $150{ }^{\circ} \mathrm{C}$ under PCI mode. This may due to the formation of the stable hydride during first cycle of hydrogenation and subsequently, there is almost no decrement of the storage capacity on further cycling. This is a common phenomenon in the case of intermettalics-based hydrogen storage materials (Shahi et al. 2011; Pandey et al. 2014). The work on these experiments on Laves-phase-based HEAs is in progress and it will be reported in future.

\section{Conclusion}

We have summarized the basic concepts related to the HEAs and also their possible utility for hydrogen storage for future applications. It has been established that the solid-state hydrogen storage is the most effective and safe storage mode. The efficient hydride-forming high-entropy materials, i.e., the elements which are strong hydride formers will be one of the superior solid-state hydrogen storage materials. It is possible that better hydrogen storage capacity can be accomplished via strain-induced distorted lattices in high-entropy materials, which could favor hydrogen atoms to occupy both the tetrahedral and octahedral sites. From the preliminary investigation reported here, the maximum storage capacity was observed to be $1.78 \mathrm{wt} \%$ in $\mathrm{Ti}-\mathrm{Zr}-\mathrm{V}-\mathrm{Cr}-\mathrm{Ni}$ equiatomic HEAs. In view of the promise and prospects of the HEAs due to their composition and structural characteristics, it may be advocated that design of hydride-forming multicomponent HEAs through suitable processing techniques may lead to a new class of useful and effective hydrogen storage materials. However, more investigations are warranted to understand the maximum capacity of hydrogen storage, absorption and desorption kinetics, stability as well as ease of utilization of stored hydrogen, for developing multicomponent HEAs as most efficient and effective hydrogen energy storage materials.

Acknowledgements The authors gratefully thank Prof. R.S. Tiwari, Prof. R.K. Mandal, Prof. B.S. Murty and Prof. M.A. Shaz, Dr. S. Mishra and Dr. Yagnesh Shadangi for many stimulating discussions at various stages of this work. NKM wishes to acknowledge the encouragement and support of Prof. K. Bhanu Shankara Rao, without which it would not have been possible to complete this article. TPY is grateful to the University Grants Commission (UGC) for the Raman Fellowship, which allowed a portion of the work to be done during fellowship. The authors would like to dedicate this article to the memory of their beloved mentor, and distinguished researcher in the area of hydrogen storage and nanomaterials, Prof. O.N. Srivastava who departed prematurely from this world on 24th April 2021 due to COVID-19.

\section{Declarations}

Conflict of Interest The authors declare no competing financial interests. 


\section{References}

Basu I, Hosson JTMD (2020) Strengthening mechanisms in high entropy alloys: fundamental issues. Scripta Mater 187:148-156. https://doi.org/10.1016/j.scriptamat.2020.06.019

Cantor B, Chang ITH, Knight P, Vincent AJB (2004) Microstructural development in equiatomic multicomponent alloys. Mater Sci Eng A 375-377:213-218. https://doi.org/10.1016/j.msea.2003.10.257

Cardoso KR, Roche V, Jorge AM, Antiqueira FJ, Zepon G, Champion Y (2021) Hydrogen storage in MgAlTiFeNi high entropy alloy. J Alloy Compd 858:158357. https://doi.org/10.1016/j.jallcom.2020.158357

de Marco MO, Li Y, Li HW, Edalati K, Floriano R (2020) Mechanical synthesis and hydrogen storage characterization of $\mathrm{MgVCr}$ and MgVTiCrFe high-entropy alloy. Adv Eng Mater 22:1901079. https://doi.org/10.1002/adem.201901079

Dewangan SK, Sharma VK, Sahu P, Kumar V (2020) Synthesis and characterization of hydrogenated novel $\mathrm{AlCrFeMnNiW}$ high entropy alloy. Int J Hydrog Energy 45:16984-16991. https://doi. org/10.1016/j.ijhydene.2019.08.113

Dornheim M, Eigen N, Barkhordarian G, Klassen T, Bormann R (2006) Tailoring hydrogen storage materials towards application. Adv Eng Mater 8(5):377-385. https://doi.org/10.1002/adem. 200600018

Edalati P, Floriano R, Mohammadi A, Li Y, Zepon G, Li HW, Edalati K (2020) Reversible room temperature hydrogen storage in highentropy alloy TiZrCrMnFeNi. Scripta Mater 178:387-390. https:// doi.org/10.1016/j.scriptamat.2019.12.009

Floriano R, Zepon G, Edalati K, Fontana GLBG, Mohammadi A, Ma Z, Li HW, Contieri RJ (2021a) Hydrogen storage properties of new $\mathrm{A}_{3} \mathrm{~B}_{2}$-type TiZrNbCrFe high-entropy alloy. Int J Hydrog Energy 46(46):23757-23766. https://doi.org/10.1016/j.ijhydene.2021.04.181

Floriano R, Zepon G, Edalati K, Fontana GLBG, Mohammadi A, Ma Z, Li HW, Contieri RJ (2021b) Hydrogen storage properties of new A3B2-type TiZrNbCrFe high-entropy alloy. Int J Hydrog Energy 46:23757-23766. https://doi.org/10.1016/j.ijhydene.2021.04.181

George EP, Curtin WA, Tasan CC (2020) High entropy alloys: a focused review of mechanical properties and deformation mechanisms. Acta Mater 188:435-474. https://doi.org/10.1016/j.actamat.2019.12. 015

Huang KH, Yeh JW (1996) A study on multicomponent alloy systems containing equal-mole elements [M.S. thesis]. Hsinchu: National Tsing Hua University

Kao Y-F, Chen S-K, Sheu J-H, Lin J-T, Lin W-E, Yeh J-W, Lin S-J, Liou T-H, Wang C-W (2010) Hydrogen storage properties of multi-principal-component $\mathrm{CoFeMnTi}_{\mathrm{x}} \mathrm{V}_{\mathrm{y}} \mathrm{Zr}_{\mathrm{z}}$ alloys. Int $\mathrm{J}$ Hydrogen Energy 35(17):9046-9059. https://doi.org/10.1016/j.ijhydene.2010.06.012

Kumar A, Shashikala K, Banerjee S, Nuwad J, Das P, Pillai CGS (2012) Effect of cycling on hydrogen storage properties of $\mathrm{Ti}_{2} \mathrm{CrV}$ alloy. Int J Hydrog Energy 37(4):3677-3682. https://doi.org/10. 1016/j.ijhydene.2011.04.135

Kunce I, Polanski M, Bystrzycki J (2013) Structure and hydrogen storage properties of a high entropy $\mathrm{ZrTiVCrFeNi}$ alloy synthesized using Laser Engineered Net Shaping (LENS). Int J Hydrog Energy 38:12180-12189. https://doi.org/10.1016/j.ijhydene.2013.05.071

Kunce I, Polanski M, Bystrzycki J (2014) Microstructure and hydrogen storage properties of a TiZrNbMoV high entropy alloy synthesized using Laser Engineered Net Shaping (LENS). Int J Hydrog Energy 39:9904-9910. https://doi.org/10.1016/j.ijhydene.2014.02.067

Miracle DB, Senkov ON (2017) A critical review of high entropy alloys and related concepts. Acta Mater 122:448-511. https://doi.org/10. 1016/j.actamat.2016.08.081

Mishra SS, Mukhopadhyay S, Yadav TP, Mukhopadhyay NK, Srivastava ON (2019) Synthesis and characterization of hexanary $\mathrm{Ti}-\mathrm{Zr}-\mathrm{V}-\mathrm{Cr}-\mathrm{Ni}-\mathrm{Fe}$ high-entropy Laves phase. J Mater Res 34(5):807-818. https://doi.org/10.1557/jmr.2018.502
Mishra SS, Yadav TP, Srivastava ON, Mukhopadhyay NK, Biswas $\mathrm{K}$ (2020) Formation and stability of C14 type Laves phase in multi component high-entropy alloys. J Alloy Compd 832:153764. https://doi.org/10.1016/j.jallcom.2020.153764

Mishra SS, Bajpai A, Biswas K (2021) TiVCrNiZrFex high entropy alloy: phase evolution, magnetic and mechanical properties. $\mathrm{J}$ Alloy Compd 871:159572. https://doi.org/10.1016/j.jallcom. 2021.159572

Montero J, Zlotea C, Ek G, Crivello JC, Laversenne L, Sahlberg M (2019) TiVZrNb multi-principal-element alloy: synthesis optimization, structural, and hydrogen sorption properties. Molecules 24:2799. https://doi.org/10.3390/molecules24152799

Montero J, Ek G, Laversenne L, Nassif V, Zepon G (2020) Hydrogen storage properties of the refractory Ti-V-Zr-Nb-Ta multi-principal element alloy. J Alloys Compound 835:155376. https://doi. org/10.1016/j.jallcom.2020.155376 (Elsevier)

Montero J, Ek G, Sahlberg M, Zlotea C (2021) Improving the hydrogen cycling properties by $\mathrm{Mg}$ addition in $\mathrm{Ti}-\mathrm{V}-\mathrm{Zr}-\mathrm{Nb}$ refractory high entropy alloy. Scripta Mater 194:113699. https://doi.org/ 10.1016/j.scriptamat.2020.113699

Mukhopadhyay NK (2015) High entropy alloys: a renaissance in physical metallurgy. Curr Sci 109(4):665-667. https://doi.org/ $10.18520 / \mathrm{cs} \% 2 \mathrm{Fv} 109 \% 2 \mathrm{Fi} 4 \% 2 \mathrm{~F} 665-667$

Mukhopadhyay NK, Yadav TP (2011) Some aspects of stability and nanophase formation in quasicrystals during mechanical milling. Israel J Chem 51(11-12):1185-1196. https://doi.org/10. 15406/mseij.2017.01.00001

Mukhopadhyay NK, Yadav TP, Srivastava ON (2002) An investigation on the transformation of the icosahedral phase in the Al-Fe$\mathrm{Cu}$ system during mechanical milling and subsequent annealing. Philos Mag A 82(16):2979-2993. https://doi.org/10.1080/01418 610208239629

Mukhopadhyay NK, Yadav TP, Srivastava ON (2003) Effects of ball milling and annealing of an alloy in the Al-Fe-Cu system: implications for phase equilibria. Philos Mag Lett 83(7):423-432. https://doi.org/10.1080/0950083031000117994

Murty BS, Yeh JW, Ranganathan S, Bhattacharjee PP (2019) High-entropy alloys. 2nd Edition Elsevier ISBN: 9780128160671. pp 1-388

Murty BS, Ranganathan S (1998) Novel materials synthesis by mechanical alloying/milling. Int Mater Rev 43(3):101-141. https://doi.org/10.1179/imr.1998.43.3.101

Pandey SK, Singh J, Yadav TP, Srivastava ON (2014) Material tailoring of $\mathrm{Ti}-\mathrm{V}-\mathrm{Fe}-\mathrm{Zr}$ for improving sorption behaviour employing off stoichiometric concentration of native element Ti. Mater Focus 3(1):28-35. https://doi.org/10.1166/mat.2014.1131

Pandey SK, Bhatnagar A, Mishra SS, Yadav TP, Shaz MA, Srivastava ON (2017) Curious catalytic characteristics of Al-Cu-Fe quasicrystal for De/rehydrogenation of $\mathrm{MgH}_{2}$. J Phys Chem C 121(45):24936-24944. https://doi.org/10.1021/acs.jpcc.7b07336

Pukazhselvan D, Sakthi SSR, Yadav TP (2012) Towards sustainable green energy development and insights on few scientific problems leading to less carbon economy. Rev Adv Sci Eng 1:302-318. https://doi.org/10.1166/rase.2012.1019

Rai DK, Yadav TP, Subrahmanyam VS, Srivastava ON (2009) Structural and Mössbauer spectroscopic investigation of Fe substituted Ti-Ni shape memory alloys. J Alloy Compd 482(1-2):28-32. https://doi.org/10.1016/j.jallcom.2009.03.164

Ranganathan S (2003) Alloyed pleasures: multimetallic cocktails. Curr Sci 85:1404-1406

Sahlberg M, Karlsson D, Zlotea C, Jansson U (2016) Superior hydrogen storage in high entropy alloys. Sci Rep. https://doi.org/10. 1038/srep36770

Sakintuna B, Lamari-Darkrim F, Hirscher M (2007) Metal hydride materials for solid hydrogen storage: a review. Int $\mathrm{J}$ Hydrog Energy 32(9):1121-1140. https://doi.org/10.1016/j.ijhydene. 2006.11.022 
Sarac B, Zadorozhnyy V, Berdonosova E, Lvanov YP, Klyamkin S, Gumrukcu S, Sarac AS, Korol A, Semenov D, Zadorozhnyy M, Sharma A, Greer AL, Eckert J (2020) Hydrogen storage performance of the multi-principal-component CoFeMnTiVZr alloy in electrochemical and gas-solid reactions. RSC Adv 10:2461324623. https://doi.org/10.1039/D0RA04089D

Sathiyamoorthi P, Kim HS (2020) High-entropy alloys with heterogeneous microstructure:processing and mechanical properties. Prog Mater Sci. https://doi.org/10.1016/j.pmatsci.2020.100709

Shahi RR, Yadav TP, Shaz MA, Srivastava ON (2008) Effects of mechanical milling on desorption kinetics and phase transformation of $\mathrm{LiNH}_{2} / \mathrm{MgH}_{2}$ mixture. Int J Hydrog Energy 33(21):61886194. https://doi.org/10.1016/j.ijhydene.2008.07.029

Shahi RR, Yadav TP, Shaz MA, Srivastava ON (2010) Studies on dehydrogenation characteristic of $\mathrm{Mg}\left(\mathrm{NH}_{2}\right)_{2} / \mathrm{LiH}$ mixture admixed with vanadium and vanadium based catalysts $\left(\mathrm{V}, \mathrm{V}_{2} \mathrm{O}_{5}\right.$ and $\left.\mathrm{VCl}_{3}\right)$. Int J Hydrog Energy 35(1):238-246. https://doi.org/10.1016/j. ijhydene.2009.10.029

Shahi RR, Yadav TP, Shaz MA, Srivastva ON (2011) Effect of processing parameter on hydrogen storage characteristics of as quenched $\mathrm{Ti}_{45} \mathrm{Zr}_{38} \mathrm{Ni}_{17}$ quasicrystalline alloys. Int J Hydrog Energy 36:592599. https://doi.org/10.1016/j.ijhydene.2010.10.031

Shahi RR, Bhatanagar A, Pandey SK, Shukla V, Yadav TP, Shaz MA, Srivastava ON (2015) $\mathrm{MgH}_{2}-\mathrm{ZrFe}_{2} \mathrm{H}_{x}$ nanocomposites for improved hydrogen storage characteristics of $\mathrm{MgH}_{2}$. Int $\mathrm{J}$ Hydrog Energy 40(35):11506-11513. https://doi.org/10.1016/j.ijhydene. 2015.03.162

Shahi RR, Yadav TP, Shaz MA, Srivastava ON (2017) Synthesis characterization and hydrogenation behaviour of as quenched $\mathrm{Ti}_{41.5+X} \mathrm{Zr}_{41.5-X} \mathrm{Ni}_{17}(x=0,3.5,11.5$ and 13.5) nano quasicrystalline ribbons. J Phys 809(1):012011. https://doi.org/10.1088/17426596/809/1/012011

Sharma AS, Yadav S, Biswas K, Basu B (2018) High-entropy alloys and metallic nanocomposites: processing challenges, microstructure development and property enhancement. Mater Sci Eng 131:1-42. https://doi.org/10.1016/j.mser.2018.04.003

Shen H, Zhang J, Hu J, Zhang J, Mao Y, Xiao H, Zhou X, Zu X (2019) A novel TiZrHfMoNb high-entropy alloy for solar thermal energy storage. Nanomaterials 9(2):248. https://doi.org/10.3390/nano9 020248

Shen H, Hu J, Li P, Huang G, Zhang J, Zhang J, Mao Y, Xiao H, Zhou X, Zu X, Long X, Peng S (2020) Compositional dependence of hydrogenation performance of Ti-Zr-Hf-Mo-Nb high-entropy alloys for hydrogen/tritium storage. J Mater Sci Technol 55:116125. https://doi.org/10.1016/j.jmst.2019.08.060

Smith CS (1963) Four outstanding researchers in metallurgical history. American Society for Testing and Materials, Baltimore

Srivastava S, Srivastava ON (1999) Synthesis, characterization and hydrogenation behaviour of composite hydrogen storage alloys, $\mathrm{LaNi}_{5} / \mathrm{La}_{2} \mathrm{Ni}_{7}, \mathrm{LaNi}_{3}$. J Alloy Compd 282:197-205. https://doi. org/10.1016/S0925-8388(98)00741-5

Srivastava ON, Yadav TP, Shahi RR, Pandey SK, Shaz MA, Bhatnagar A (2015) Hydrogen energy in India: storage to application. Proc Indian Natl Sci Acad 81(4):915-937. https://doi.org/10.16943/ ptinsa/2015/v81i4/48303

Strozi RB, Leiva DR, Huot J, Botta WJ, Zepon G (2021) Synthesis and hydrogen storage behavior of $\mathrm{Mg}-\mathrm{V}-\mathrm{Al}-\mathrm{Cr}-\mathrm{Ni}$ high entropy alloys. Int J Hydrog Energy 46:2351-2361. https://doi.org/10. 1016/j.ijhydene.2020.10.106

Switendick AC (1979) Band structure calculations for metal systems. Z Phys Chem. https://doi.org/10.1524/zpch.1979.117.117.089

Tsai MH, Yeh JW (2014) High-entropy alloys: a critical review. Mater Res Lett 2(3):107-123. https://doi.org/10.1080/21663831.2014. 912690
Vaidya M, Muralikrishna GM, Murty BS (2019) High-entropy alloys by mechanical alloying: a review. J Mater Res 34(5):664-686. https://doi.org/10.1557/jmr.2019.37

Verma SK, Bhatnagar A, Shukla V, Soni PK, Pandey AP, Yadav TP, Srivastava ON (2020) Multiple improvements of hydrogen sorption and their mechanism for $\mathrm{MgH}_{2}$ catalyzed through $\mathrm{TiH}_{2} @$ Gr. Int J Hydrog Energy 45(38):19516-19530. https://doi.org/10. 1016/j.ijhydene.2020.05.031

Vincent AJB, Cantor B (1981) BSc Thesis, University of Sussex.

Westlake DG (1983) A geometric model for the stoichiometry and interstitial site occupancy in hydrides (deuterides) of $\mathrm{LaNi}_{5}$, LaNi4Al and $\mathrm{LaNi}_{4} \mathrm{Mn}$. J Less-Common Metals 91:275-292

Yadav TP, Shahi RR, Srivastava ON (2012a) Synthesis, characterization and hydrogen storage behaviour of $\mathrm{AB}_{2}\left(\mathrm{ZrFe}_{2}\right.$, $\mathrm{Zr}\left(\mathrm{Fe}_{0.75} \mathrm{~V}_{0.25}\right)_{2}, \mathrm{Zr}\left(\mathrm{Fe}_{0.5} \mathrm{~V}_{0.5}\right)_{2}$ type materials. Int $\mathrm{J}$ Hydrog Energy 37:3689-3696. https://doi.org/10.1016/j.ijhydene.2011.04.210

Yadav TP, Yadav RM, Singh DP (2012b) Mechanical milling: a topdown approach for the synthesis of nanomaterials and nanocomposites. Nanosci Nanotechnol 2(3):22-48. https://doi.org/10. 5923/j.nn.20120203.01

Yadav TP, Mukhopadhyay S, Mishra SS, Mukhopadhyay NK, Srivastava ON (2017) Synthesis of a single phase of high-entropy Laves intermetallics in the Ti-Zr-V-Cr-Ni equiatomic alloy. Philos Mag Lett 97(12):494-503. https://doi.org/10.1080/09500839.2017. 1418539

Yadav TP, Awasthi K (2020) Hydrogen energy: a clean and green fuel. Environmental aspect of alternative energy sources. New Delhi, (India) Bharti Publications. ISBN: 978-93-89657-43-2. pp 30-38

Yan X, Zhang Y (2020) Functional properties and promising applications of high entropy alloys. Scripta Mater 187:188-193. https:// doi.org/10.1016/j.scriptamat.2020.06.017

Ye YF, Wang Q, Lu J, Liu CT, Yang Y (2016) High-entropy alloy: challenges and prospects. Mater Today 19:349-362. https://doi. org/10.1016/j.mattod.2015.11.026

Yeh JW, Chen SK, Gan JY, Lin SJ, Chin TS, Shun TT, Tsau CH, Chou SY (2004a) Formation of simple crystal structures in $\mathrm{Cu}-\mathrm{Co}-$ $\mathrm{Ni}-\mathrm{Cr}-\mathrm{Al}-\mathrm{Fe}-\mathrm{Ti}-\mathrm{V}$ alloys with multiprincipal metallic elements. Metall Mater Trans A 35:2533-2536. https://doi.org/10.1007/ s11661-006-0234-4

Yeh JW, Chen SK, Lin SJ, Gan JY, Chin TS, Shun TT, Tsau CH, Chang SY (2004b) Nanostructured high-entropy alloys with multiple principal elements: novel alloy design concepts and outcomes. Advanced engineering materials 6:299303. Z Phys Chem 117:89112. https://doi.org/10.1002/adem.200300567

Zeng Z, Xiang M, Zhang D, Shi J, Wang W, Tang X, Tang W, Ma X, Chen Z, Wang Y (2021) Effects of additional element on mechanical properties of the Cantor alloy: a review. J Market Res 15:1920-1934. https://doi.org/10.1016/j.jmrt.2021.09.019

Zepon G, Leiva DR, Strozi RB, Bedoch A, Figueroa SJA, Ishikawa TT, Botta WJ (2018) Hydrogen-induced phase transition of $\mathrm{MgZrTiFe}{ }_{0.5} \mathrm{Co}_{0.5} \mathrm{Ni}_{0.5}$ high entropy alloy. Int J Hydrog Energy 43:1702-1708. https://doi.org/10.1016/j.ijhydene.2017.11.106

Zhang C, Wu Y, You L, Cao X, Lu Z, Song X (2019) Investigation on the activation mechanism of hydrogen absorption in TiZrNbTa high entropy alloy. J Alloy Compd 781:613-620. https://doi.org/ 10.1016/j.jallcom.2018.12.120

Zlotea C, Sow MA, Ek G, Couzinié JP, Perrière L, Guillot I, Bourgon J, Møller KT, Jensen TR, Akiba E, Sahlberg M (2018) Hydrogen sorption in TiZrNbHfTa high entropy alloy. J Alloys Compd 775:667-674. https://doi.org/10.1016/j.jallcom.2018.10.108 (Elsevier)

Publisher's Note Springer Nature remains neutral with regard to jurisdictional claims in published maps and institutional affiliations. 